\title{
INVESTIGATING THE BEHAVIOR OF SPECIALLY PRE-FABRICATED STEEL MOMENT CONNECTION UNDER CYCLIC LOADING
}

\author{
Morteza Kazemi Torbaghan ${ }^{1}$, Mohammad Reza Sohrabi ${ }^{2,{ }^{*}}$ and Hasan Haji Kazemi ${ }^{3}$ \\ ${ }^{1}$ Department of Civil Engineering, University of Sistan and Baluchestan, Zahedan, Iran \\ ${ }^{2}$ Associate Professor, Department of Civil Engineering, University of Sistan and Baluchestan, Zahedan, Iran \\ ${ }^{3}$ Professor, Department of Civil Engineering, Ferdowsi University, Mashhad, Iran \\ *(Corresponding author: E-mail: sohrabi@hamoon.usb.ac.ir)
}

Received: 10 June 2016; Revised: 9 July 2017; Accepted: 16 September 2017

\begin{abstract}
The connections of pre-fabricated steel structures have become a major issue in recent decades due to the need for rapid constructions. In the past years, several studies have been conducted with the aim of developing simple and efficient connections. Here, a new modularized pre-fabricated steel moment connection is proposed, which is composed of a short column with a pyramid head for a fast and easy assembling. In this paper, the behavior of this connection is investigated through using several cross-section shapes and plates with different thickness. The obtained force-displacement and moment-rotation curves of the connection under cyclic loads indicate that a 20 percent increase in the thickness of the beam and column connection plates raises the yielding moment, yielding rotation and the maximum rotation capacity of the connection by 21,19 and 13 percent respectively. The results also suggest that the proposed model has a higher capacity as well as reliable performance comparing to other moment connections.
\end{abstract}

Keywords: Special steel moment connection, pre-fabricated structures, force-displacement curve, cyclic loads, moment-displacement curve

DOI: 10.18057/IJASC.2018.14.3.6

\section{INTRODUCTION}

Since the traditional construction methods are not efficient for today's requirements, the use of modern materials and techniques is essential. Compared to traditional methods, modularized pre-fabricated structures offer several benefits such as low costs and fast construction and implementation procedures. The components of the connection in the modularized pre-fabricated steel structural are composed of beam and column connection plates and a short column. In this form, the floor slabs can be constructed completely in factory and then carried to the site and placed on the columns. The implementation of the pre-fabricated floor slabs is difficult, particularly on the upper floors. Therefore, a new method for faster and easier floor assembly has been developed in which a pyramidal section is provided on the connection plate of the lower-floor column in a way that during the floor slabs implementation, the pyramidal section is placed into the short column. Figure 1 indicates the components of the proposed moment connection and the implementation process using the pyramidal section. 


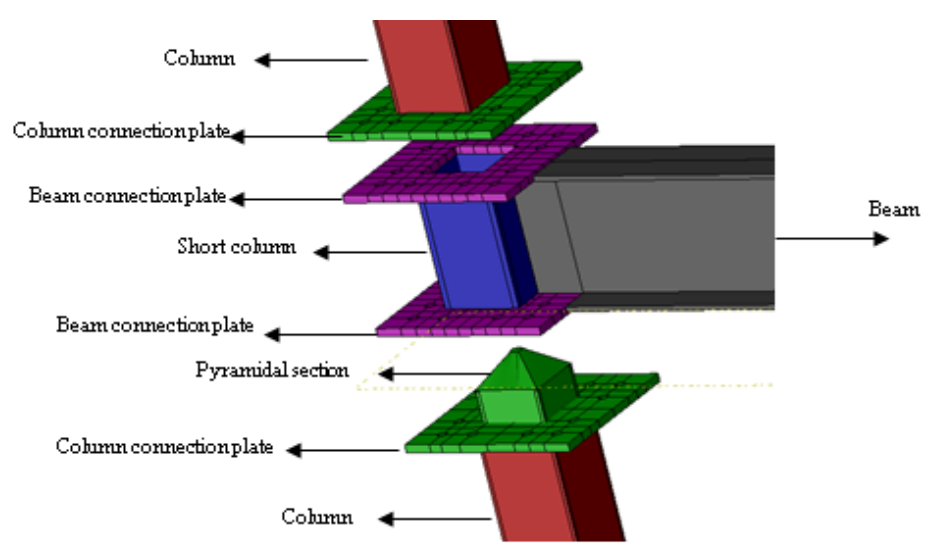

Figure 1. Components of the Proposed Connection and Implementation Process

In this study, the force-displacement curves obtained by applying cyclic loads were used for evaluating the capacity and ductility of the connections. Additionally, the effect of using stiffener and pyramidal section as well as changing the thickness of beam and column connection plates on the behavior of the connection under cyclic loads was investigated. For this purpose, a 3D finite element model was developed in ABAQUS and the results were verified using experimental data.

Despite the fact that pre-fabricated assemblies are a challenging area for research, a few studies have been conducted on the moment connection of these structures thus far. Generally, the main focus has usually been on the beam to column connection components since it is one of the main parts of the structure (Liu et al. [1]). The studies have been mostly conducted using finite element method as well as experimental tests in which different properties of various moment connection types with innovative configuration have been assessed. Since the proposed pre-fabricated steel moment connection has never been studied before, in this paper the most related literatures were reviewed to present a more comprehensive view of this connection.

The behavior of moment connections has been investigated by many scholars using different methods. Ghassemieh et al. [2] studied the seismic behavior of extended endplate moment connections. In their research, a test setup was modeled and the connections were analyzed using ANSYS and the model was validated by comparing the results with experimental data. Then, the effect of changing the dimension of the connection components on the overall seismic performance of the connection was investigated. Popov and Tsai [3] also evaluated the cyclic behavior of extended endplate moment connection and suggested that the methods which used the results of monotonic loading for the design of connections in seismic regions may need to be revised. Maggi et al. [4] used ANSYS for modeling moment connections and compared the FEM outcomes with experimental results obtained from monotonic loading. By using ABAQUS, Alhendi and Celikag [5] improved the moment-rotation curves of reverse channel connection by changing its geometrical shape. Kulkarni and Gaurang [6] also studied the reduced beam section steel moment connections (RBS) fabricated from Indian sections and analyzed them under cyclic loads. Their findings showed that the RBS connections have an acceptable capacity under this type of loading. Gerami et al. [7] studied the effect of bolts arrangement in extended endplate and T-stub connection under cyclic loads using ABAQUS. In their study, 14 specimens of these connections were modeled by changing the horizontal and vertical arrangement of the bolts. The behavior of bolted T-stub connections with welded plates was also experimentally investigated by Coelho et al. [8].

Brunesi et al. [9] evaluated the performance of partially-restrained bolted beam-to-column connections under cyclic loads and proposed an alternative and conservative method for a quick rotational stiffness estimation of these PR bolted top-and-seat angle connections. Arul Jayachandran et al. [10] studied the behavior of semi-rigid endplate connections by experimentally 
and numerically evaluating the moment-rotation behavior of semi-rigid bolted endplate connections. All the specimens were modeled using ABAQUS. Brunesi et al. [11] evaluated the seismic performance of MRFs with partially-restrained bolted beam-to-column connections through FE analyses. Pucinotti [12] predicted the cyclic moment-rotation behavior of top-and-seat and web angle connection using a mechanical model. The results of their analyses showed that the simple mechanical model yields the results that are reasonably consistent with the experimental data and are more accurate than the results of the Eurocode 3.

Among these studies, the most relevant works have been performed by Liu et al. $[1,13,14]$ on the pre-fabricated steel moment connections. In 2015, Liu et al. [13] studied the seismic behavior of welded joints in modularized pre-fabricated steel structures. The model was analyzed under monotonic and cyclic load using finite element method. In another study from these authors (Liu et al [1]), the bolted-welded beam to column joint for the modularized pre-fabricated steel structures was studied. The properties of the connection behavior including static performance, hysteretic performance, skeleton curves, ductile performance, energy dissipation capacity and rotation capacity were assessed using both finite element and experimental methods. The effect of the thickness of the components as well as the welding capacity was also investigated. In order to fulfil all aspects of their studies, simplified formulas were developed to measure the load-bearing capacity of the connection. Liu et al. [14] furthered their works by studying the pre-fabricated bolted connections for multi-rise and high-rise structures. For this purpose, finite element and experimental analyses were performed and the results were compared to develop the finite element modeling. This was established to determine the mechanical properties of the connection which were difficult to be studied through experimental tests.

All these studies indicated the capability of finite element software packages like ABAQUS to yield valid results comparing to experimental tests. In this study, finite element method was employed and the results were then compared with the experimental data to investigate the different properties of the proposed moment connection.

\section{MODELING}

In order to validate the finite element models, the numerical results were first compared with the experimental results of the Specimen from Yang and Kim research [15]. Figure 2 represents the selected moment frame, dimensions, the section of beam and columns, and the model of the exterior joint.

The entire components used in this research including columns, beams, connection plates, stiffeners and boxes were made of SS400 steel. The bolts were also A490. The mechanical properties of all materials were taken from the experimental specimens mentioned in Table 1. (Yang and Kim [15]). Modulus of elasticity and the Poisson's ratio for all sections were $200 \mathrm{Gpa}$ and 0.3 respectively. Loads were included by applying the corresponding displacement at the end of the beam according to the experimental set-up and the loading protocol of ATC-24 [16] which is presented in Table 2.
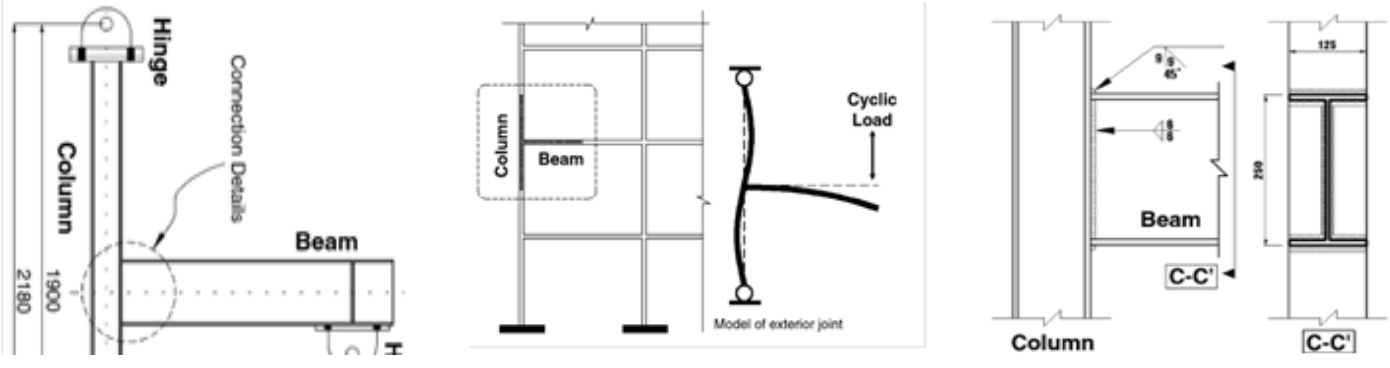
(b)

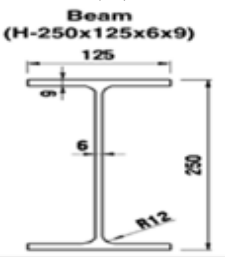

(a)

(d) (c)

Column

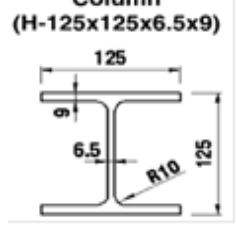

(e)

Figure 2. Model Feature and Configuration, a: Test set-up, b: Model of the Exterior Joint,

c: Beam to Column Connection Type, d: Beam Section, e: Column Section

Table 1. Material Properties of Numerical and Experimental Specimens (Yang and Kim [15])

\begin{tabular}{cccc}
\hline Material & Application & Strain & Stress (MPa) \\
\hline \multirow{2}{*}{ SS400 } & Beam, column, & 0.00178 & 332 \\
\cline { 2 - 4 } & plate, box & 0.0196 & 332 \\
\cline { 3 - 4 } & & 0.2134 & 450 \\
\hline
\end{tabular}

Table 2. Values of Displacements Applied to the End of the Beam (ATC-24 [16])

\begin{tabular}{rrrrrrrrrrrrrrr}
\multicolumn{10}{c}{ Table 2. Values of Displacements Applied to the End of the Beam (ATC-24 [16]) } \\
\hline Step no. & 1 & 2 & 3 & $\ldots$ & 6 & $\ldots$ & 9 & 10 & $\ldots$ & 13 & 14 & $\ldots$ & 18 \\
\hline $\begin{array}{r}\text { Displacement } \\
(\mathbf{m m})\end{array}$ & \pm 3 & \pm 6 & \pm 9 & $\ldots$ & \pm 18 & $\ldots$ & \pm 30 & \pm 35 & $\ldots$ & \pm 50 & \pm 60 & $\ldots$ & \pm 100 \\
\hline Drift (rad. \%) & .324 & .649 & .973 & $\ldots$ & 1.95 & $\ldots$ & 3.24 & 3.78 & $\ldots$ & 5.41 & 6.49 & $\ldots$ & 10.81 \\
\hline
\end{tabular}

The force-displacement curves are presented for the experimental and numerical specimens in Figure 3. It can be seen that there is a good agreement between experimental and numerical results.

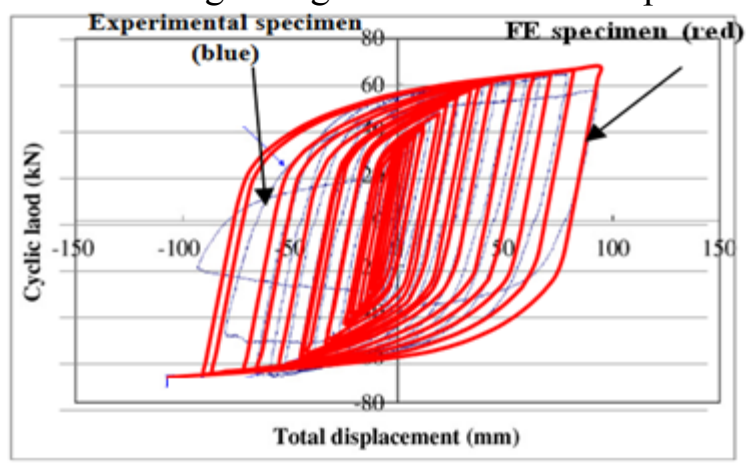

Figure 3. Force-displacement Curves for Experimental and FE Specimens 


\section{CONNECTION}

All properties of the connection including steel property, beam section, beam and column length, loading and support conditions were similar to the experimental sample except that the column was a box-section type. Such a profile was selected to ease the assembling procedure since the section of the short column was also box-shaped. Other dimensions of connection can be seen in Table 3 and Figure 4. For FE modeling, shell and solid elements were used for sections and bolts respectively. All the connecting assemblies were modeled using S4R while C3D8R which refers to continuum three dimensional 8-noded brick element with reduced order integration was used for modeling the bolts. The latter has three degrees of freedom at each node and translations in the nodal $\mathrm{x}, \mathrm{y}, \& \mathrm{z}$ direction (Jayachandran et al. [10]). For applying structure mesh technique, sections were created separately and then tied together. The holes were standard and loading was performed in two steps. In the first step, according to the types and sizes of the bolts, pre-tension force equal to $107 \mathrm{kN}$ was applied to all bolts (Salmon et al. [17]) and in the second step the displacement was applied to the end of the beam. The type of contact between bolts and connection plates was "penalty" with a friction coefficient of 0.5 (Salmon et al. [17]). The names and properties of the specimens were presented in Table 4.

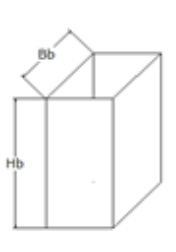

a

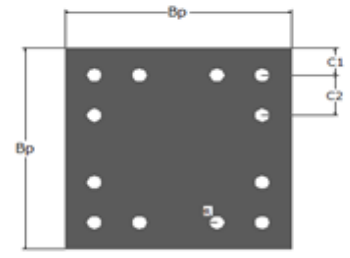

b

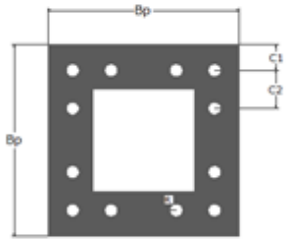

c

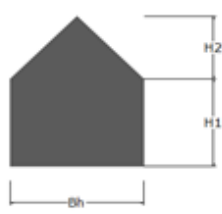

d

Figure 4. Dimension of the Connection Component, a: Short Column, b: Column Connection Plat, c: Beam Connection Plate, d: Pyramidal Section

Table 3. Geometry and Dimensions of the Connection Component (parameters was shown in Figure 4)

\begin{tabular}{|c|c|}
\hline Element & Section size (mm) \\
\hline Column & $\begin{array}{c}13.53 \times 13.53 \times 5.85 \\
\square\end{array}$ \\
\hline Column connection plate & $\begin{array}{c}\mathrm{Bp}=300, \mathrm{C} 1=30, \mathrm{C} 2=40, \mathrm{R}=9, \\
\mathrm{t}=\text { variable }\end{array}$ \\
\hline Beam connection plate & $\begin{array}{c}\mathrm{Bp}=300, \mathrm{C} 1=30, \mathrm{C} 2=40, \mathrm{R}=9 \\
\mathrm{t}=\text { variable }\end{array}$ \\
\hline Box & $\mathrm{Bb}=150, \mathrm{Hb}=232, \mathrm{t}=10$ \\
\hline pyramidal section & $\mathrm{Bh}=148, \mathrm{H}_{1}=100, \mathrm{H}_{2}=100$ \\
\hline Bolt & $\mathrm{D}=16$ \\
\hline
\end{tabular}


Table 4. Properties of Specimens

\begin{tabular}{ccccc}
\hline & \multicolumn{4}{c}{ Properties } \\
\cline { 2 - 5 } Specimens & $\begin{array}{c}\text { Column } \\
\text { section }\end{array}$ & $\begin{array}{c}\text { Thickness of } \\
\text { connection plates } \\
(\mathrm{mm})\end{array}$ & $\begin{array}{c}\text { Pyramidal } \\
\text { section }\end{array}$ & Stiffener \\
\hline Numerical & I shape & - & - & - \\
\hline $\mathrm{Ct12}$ & Box & 12 & - & - \\
\hline $\mathrm{Ct15}$ & Box & 15 & - & - \\
\hline $\mathrm{Ct1} 18$ & Box & 18 & - & - \\
\hline $\mathrm{Ct} 15 \mathrm{P}$ & Box & 15 & available & - \\
\hline $\mathrm{Ct} 15 \mathrm{~S}$ & Box & 15 & - & available \\
\hline $\mathrm{Ct} 15 \mathrm{I}$ & I shape & 15 & - & - \\
\hline
\end{tabular}

In $\mathrm{Ct} 12$ specimen, when the amount of the applied force reached up to $55.03 \mathrm{kN}\left(\mathrm{P}_{\mathrm{y}}=55.03 \mathrm{kN}\right)$, the first section that yielded was the parts of the column connection plates. As the force increased, the yielding area expanded and other sections began to yield as well. When force was $95.45 \mathrm{kN}$, the stress in column and beam connection plates reached its maximum capacity and the plates could not bear more forces. As a result, the thickness of the connection plates in this specimen was not suitable. Figure 5 represents Von Mises stress distribution in a connection when force was $95.45 \mathrm{kN}$ and Figure 6 represents the force-displacement curve at the end of the beam.
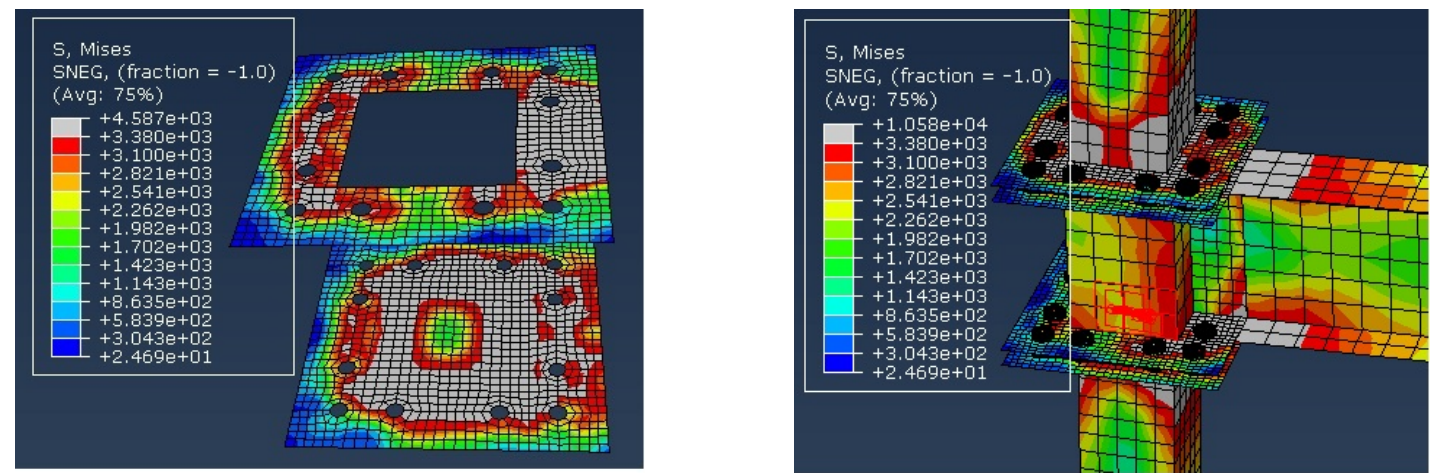

Figure 5. Contour Plot for Von Mises Stress Distribution in Ct12 (unit: $\mathrm{kg} / \mathrm{cm}^{2}$ )

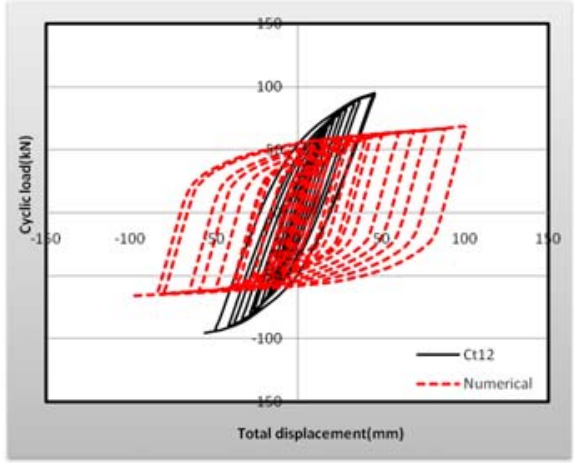

Figure 6. Force-displacement Curves for Ct12 and Numerical Specimens

Figure 6 implies that the load bearing capacity of $\mathrm{Ct} 12$ was more than the numerical model (the verified model) while it could not bear $100 \mathrm{~mm}$ displacement due to the failure of the beam and column connection plates.

In $\mathrm{Ct15}$, when the amount of the applied force reached up to $71.62 \mathrm{kN}\left(\mathrm{P}_{\mathrm{y}}=71.62 \mathrm{kN}\right)$, the first sections that yielded were some parts of the column connection plates. As the force increased, other 
sections began to yield as well. In the last step (displacement was $100 \mathrm{~mm}$, force was $114.25 \mathrm{kN}$ ), the large areas of the connection plates, columns and beam yielded without any failure. Figure 7 represents the force-displacement curve at the end of the beam.

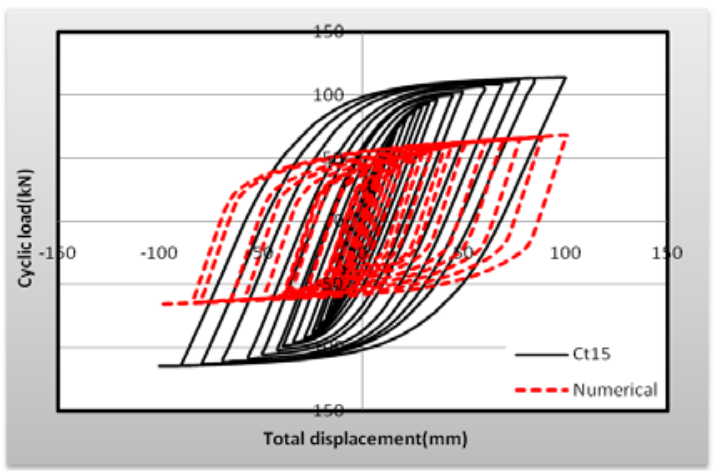

Figure 7. Force-displacement Curves for Ct15 and Numerical Specimens

Figure 7 indicates that $\mathrm{P}_{100}$ (the amount of force multiplied by the $100 \mathrm{~mm}$ displacement at the end of the beam) was 114.25 and $65.92 \mathrm{kN}$ for $\mathrm{Ct} 15$ and the numerical specimen respectively. Figures 8 to 12 show the Von Mises stress distribution and force-displacement curves for other specimens and table 5 shows the values of $\mathrm{P}_{\mathrm{y}}, \mathrm{P}_{100}$ and $\mathrm{P}_{\text {failure }}$ for all of the specimens.

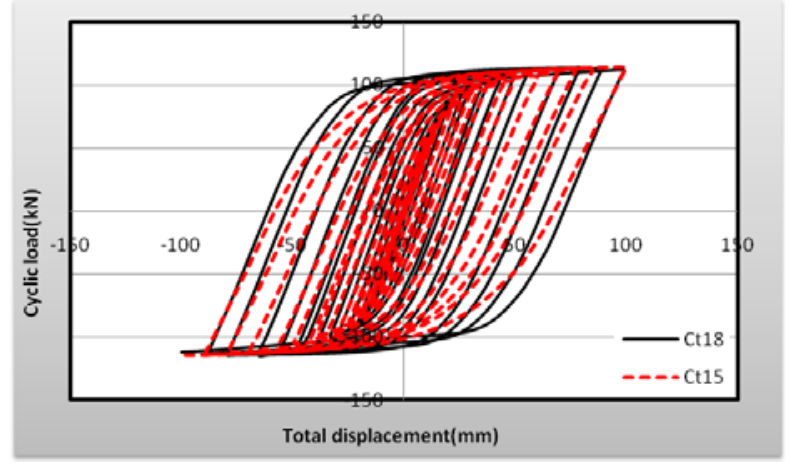

Figure 8. Force-displacement Curves for $\mathrm{Ct} 18$ and $\mathrm{Ct} 15$

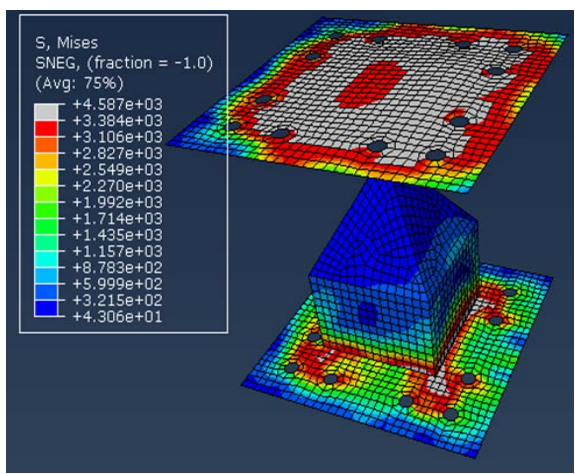

Figure 9. Contour Plot for Von Mises Stress Distribution in Ct15P (unit: $\mathrm{kg} / \mathrm{cm}^{2}$ )

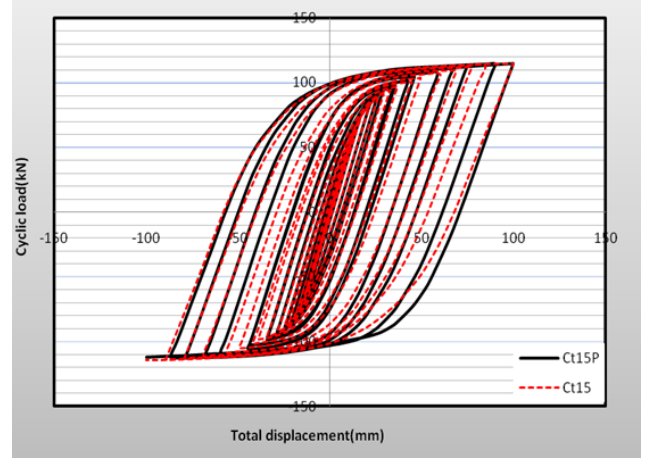

Figure 10. Force-displacement Curves for $\mathrm{Ct} 15$ and $\mathrm{Ct} 15 \mathrm{P}$ 


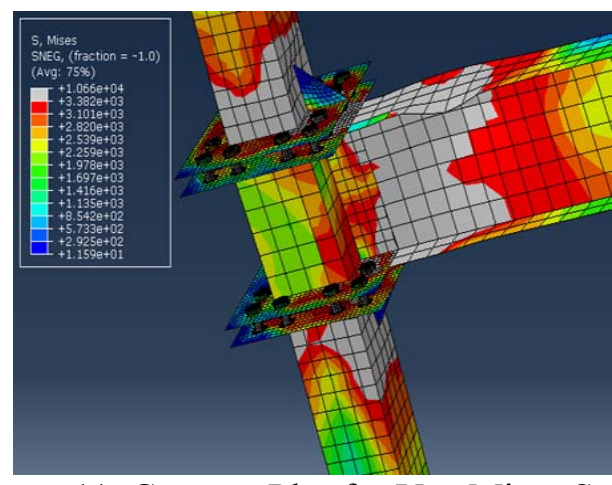

Figure 11. Contour Plot for Von Mises Stress Distribution in Ct15S (unit: $\mathrm{kg} / \mathrm{cm}^{2}$ )

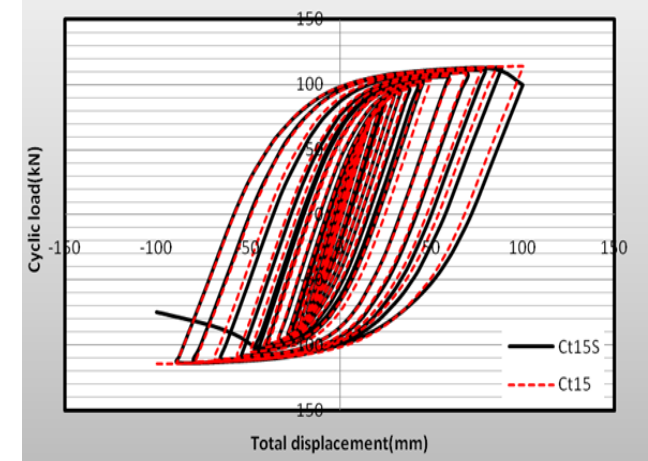

Figure 12. Force-displacement Curve for $\mathrm{Ct} 15$ and $\mathrm{Ct} 15 \mathrm{~S}$

In Ct15I, when the applied force reached up to $57.86 \mathrm{kN}$, the first section that yielded was the parts of column connection plates. As the applied force became $104.69 \mathrm{kN}$ (displacement is $90 \mathrm{~mm}$ ), some parts of the column connection plates failed and the connection reached its ultimate capacity. Figure 13 shows Von Mises stress distribution in the connection when displacement was $90 \mathrm{~mm}$ and Figure 14 shows the force-displacement curve at the end of beam.

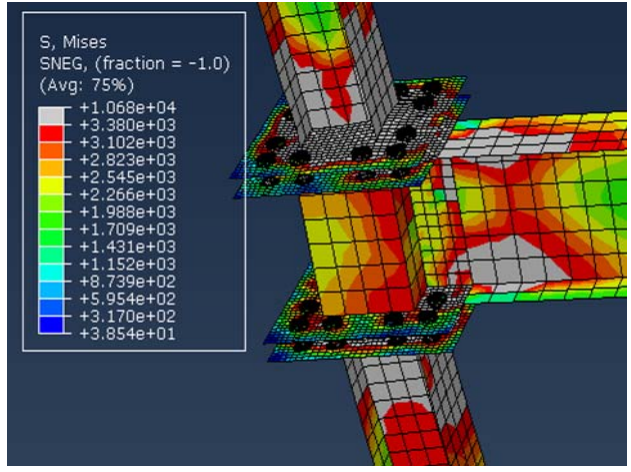

Figure 13. Contour Plot for Von Mises Stress Distribution in Ct15I Specimen (unit: $\mathrm{kg} / \mathrm{cm}^{2}$ )

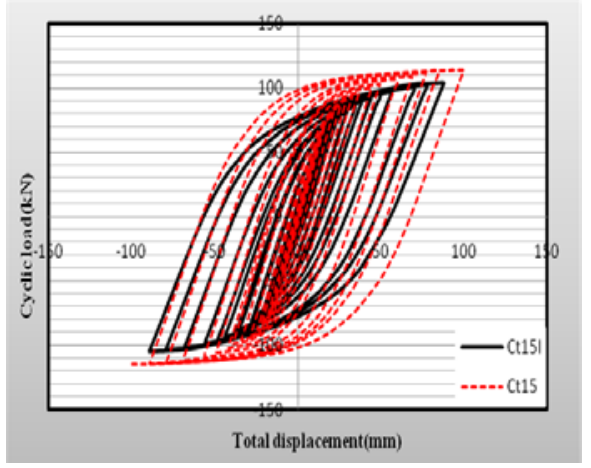

Figure 14. Force-displacement Curve for Ct15I and Ct15 Specimens

Table 5. Values of $\mathrm{P}_{\mathrm{y}}, \mathrm{P}_{100}$ and $\mathrm{P}_{\text {failur }}$

\begin{tabular}{cccc}
\hline specimens & $\mathbf{P}_{\mathbf{y}}(\mathbf{k N})$ & $\mathbf{P}_{\mathbf{1 0 0}}(\mathbf{k N})$ & $\mathbf{P}_{\text {failur }}(\mathbf{k N})$ \\
\hline $\mathbf{C t 1 2}$ & 55.03 & - & 95.45 \\
\hline $\mathbf{C t 1 5}$ & 71.62 & 114.25 & No failure \\
\hline Ct18 & 86.24 & 111.64 & No failure \\
\hline Ct15P & 71.62 & 111.9 & No failure \\
\hline Ct15S & 71.39 & 99.7 & No failure \\
\hline Ct15I & 57.86 & - & 104.69 \\
\hline
\end{tabular}

\section{EXPERIMENTAL AND NUMERICAL SKELETON CURVES}

In this section, experimental skeleton curves for the three connection types (Yang and Kim [15]) are presented and then compared with the curves of pre-fabricated steel pyramidal special connections. The detail of the DWA and TSD joints is given in Figure 15. 


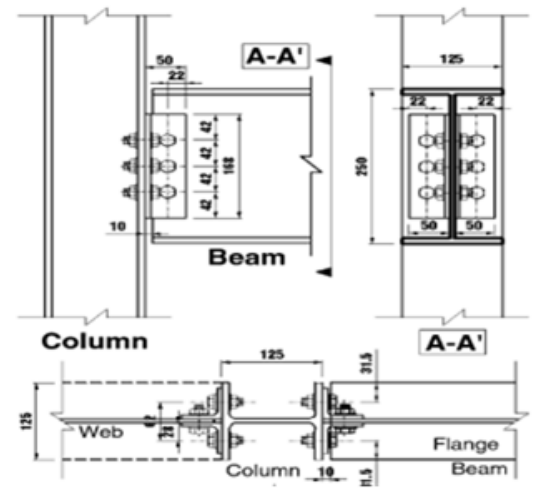

(a)

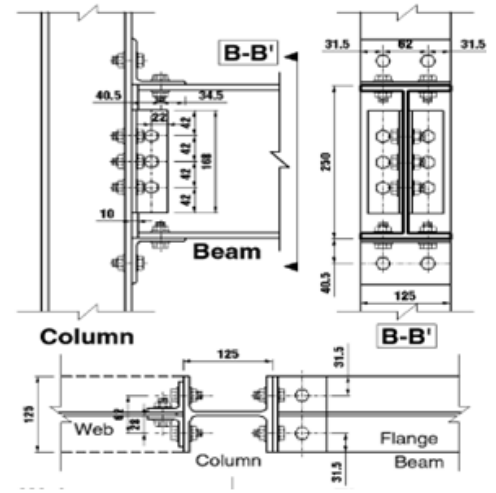

(b)

Figure 15. Details and Dimensions of Connections. a: DWA, b: TSD (Yang and Kim [15])

For a progressive sequence of compression and tension, the line joining the peak points in the load-displacement curve of each loading sequence forms the skeleton curve. In many cases, the skeleton curve coincides with the monotonic loading curve (Popov and Takhirov [18], SAC Joint Venture [19]). Figures 16 and 17 represent the skeleton curves of experimental and numerical specimens respectively.

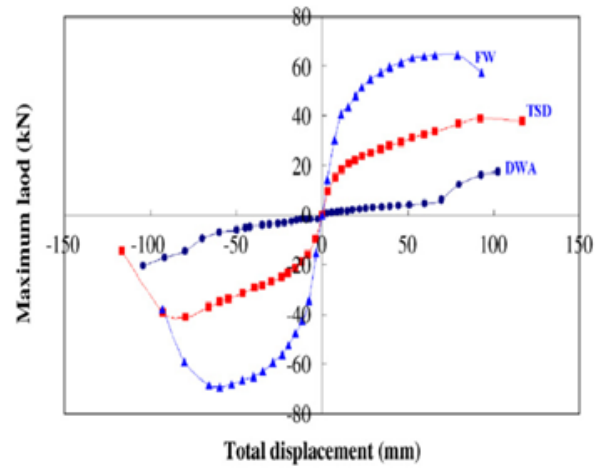

Figure 16. Skeleton Curves of Load Displacement of Experimental Specimens (Yang and Kim [15])

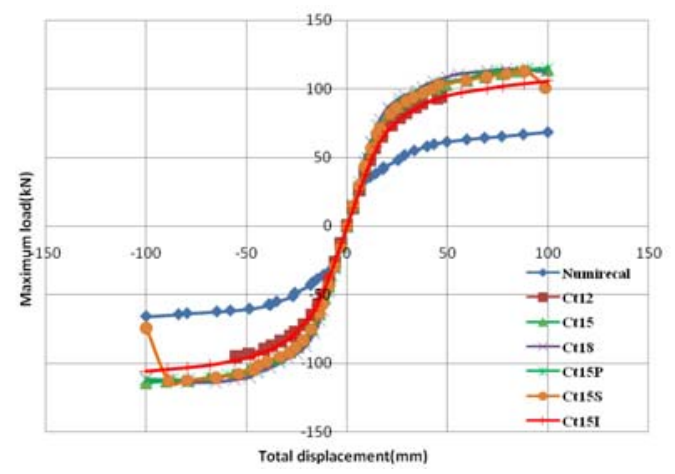

Figure 17. Skeleton Curves of Load Displacement of Numerical Specimens

According to the Figures 5 to 17, pre-fabricated steel connections had a high capacity under cyclic loads such that most specimens could bear $100 \mathrm{~mm}$ displacement $(10.81 \%$ drift $)$ at the end of the beam without a decrease under the applied force. Since these connections were composed of many components, the moment redistribution occurred which postponed the failure mechanism and increased the load bearing capacity of the connection.

\section{MOMENT- ROTATION BEHAVIOR}

In this section, the flexural and rotational behavior of the connections was evaluated for all of the specimens. Figure 18 demonstrates the calculation of rotational capacity $(\theta \mathrm{z})$ under the applied force to the end of the beam. The results were presented in Table 6 in which $M_{y}$ and $R_{y}$ represent the yielding moment and yielding rotation while $\mathrm{M}_{\max }$ and $\mathrm{R}_{\max }$ are the maximum moment and rotation of the specimens respectively. 


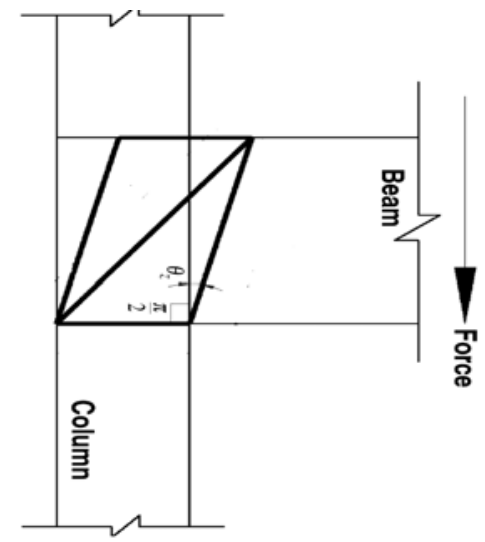

Figure 18. Calculation of Connection Rotation Capacity (Yang and Kim [15])

Table 6. Moment- Rotation Behavior of the Connections

\begin{tabular}{|c|c|c|c|c|c|c|c|c|}
\hline Specimens & $\begin{array}{c}\mathbf{M}_{\mathbf{y}} \\
(\mathbf{k N} \cdot \mathrm{m})\end{array}$ & $\begin{array}{c}\mathbf{R}_{\mathbf{y}} \\
\text { (Rad.) }\end{array}$ & $\begin{array}{c}M_{\max } \\
(\mathbf{k N} \cdot \mathbf{m})\end{array}$ & $\begin{array}{c}\mathbf{R}_{\max } \\
\text { (Rad.) }\end{array}$ & $\begin{array}{l}\text { Percentage of } \\
\text { increment/ } \\
\text { decrement } \\
\text { compared to } \\
\text { the FW } \\
\text { specimen }\left(M_{y}\right)\end{array}$ & $\begin{array}{l}\text { Percentage of } \\
\text { increment/ } \\
\text { decrement } \\
\text { compared to the } \\
\text { FW } \\
\text { specimen(M }\left(M_{\max }\right)\end{array}$ & $\begin{array}{l}\text { Percentage of } \\
\text { increment/ } \\
\text { decrement } \\
\text { compared to } \\
\text { the } F W \\
\text { specimen }\left(R_{\mathrm{y}}\right)\end{array}$ & $\begin{array}{c}\text { Percentage of } \\
\text { increment/ } \\
\text { decrement } \\
\text { compared to the } \\
\text { FW } \\
\text { specimen( }\left(R_{\max }\right) \\
\end{array}$ \\
\hline Ct12 & 50.9 & 0.01053 & 88.28 & 0.0474 & +28.86 & +41.25 & +229.1 & +110.7 \\
\hline Ct15 & 66.25 & 0.01266 & 107.63 & 0.0795 & +67.72 & +72.2 & +295.65 & +253.3 \\
\hline Ct18 & 79.77 & 0.0151 & 103.26 & 0.0898 & +101.9 & +65.22 & +371.9 & +299.1 \\
\hline Ct15H & 65.99 & 0.01196 & 103.5 & 0.0896 & +67.06 & +65.6 & +273.7 & +298.2 \\
\hline Ct15S & 66.03 & 0.01258 & 104.89 & 0.06 & +67.16 & +65 & +293.1 & +166.7 \\
\hline Ct15I & 53.52 & 0.01201 & 96.83 & 0.0702 & +35.5 & +54.9 & +275.3 & +212 \\
\hline FW[15] & 39.5 & 0.0032 & 62.5 & 0.0225 & - & - & - & - \\
\hline DWA[15] & 1.1 & 0.0027 & 17.7 & 0.1073 & -97.21 & -71.7 & -15.6 & +376.9 \\
\hline TSD[15] & 15.3 & 0.0069 & 36.6 & 0.0856 & -61.27 & -41.44 & +115.6 & +280.4 \\
\hline
\end{tabular}

According to Table 6, by increasing the thickness of the connection plates; $M_{y}, R_{\max }$ and $R_{y}$ were increased. The maximum rotation capacity was increased by using pyramidal section while it was reduced through applying the stiffener. The Table 6 also shows that all pre-fabricated connections had a high capacity such that in all specimens, $M_{y}$ and $M_{\max }$ were higher and $R_{y}$ and $R_{\max }$ were lower than FW moment and rotation capacity respectively. Based on this, the pre-fabricated demonstrated a high rotational capacity as well as adequate ductility.

\section{CONCLUSION}

In this paper, the effects of the thickness of the beam, column, connection plates and the stiffeners as well as the pyramidal section on the force-displacement curve of the pre-fabricated steel moment connection under cyclic loads were investigated. For this purpose, the connection was modeled and analyzed using ABAQUS and the model was compared and validated with several experimental specimens. The main results of this study can be summarized as follows:

1. In this connection, the beam and column connection plates are the first sections that yield which implies that the thickness of these plates has a negligible effect on the maximum moment capacity $\left(\mathrm{M}_{\max }\right)$ while increases the yielding moment capacity $\left(\mathrm{M}_{\mathrm{y}}\right)$ of the connection. Based on the experimental results, $\mathrm{M}_{\mathrm{y}}$ of $\mathrm{Ct} 12, \mathrm{Ct} 15$ and $\mathrm{Ct} 18$ is $50.9 \mathrm{kN} . \mathrm{m}$, $66.25 \mathrm{kN} . \mathrm{m}$ and $79.77 \mathrm{kN} . \mathrm{m}$ respectively. In addition, increasing the thickness of the plates from $12 \mathrm{~mm}$ to $15 \mathrm{~mm}$ and $18 \mathrm{~mm}$ raises $\mathrm{M}_{\mathrm{y}}$ by 30.2 percent and 56.72 percent respectively. It also increases $\mathrm{R}_{\mathrm{y}}$ of $\mathrm{Ct} 12$ from 0.01053 radian to 0.01266 and 0.0151 radian and $\mathrm{R}_{\max }$ of $\mathrm{Ct} 12$ from 0.0474 radian to 0.0795 and 0.0898 radian for $\mathrm{Ct} 15$ and 
Ct18 respectively, which means that $\mathrm{R}_{\mathrm{y}}$ grows to 20.23 and 43.4 percent while $\mathrm{R}_{\max }$ is increased by 67.72 and 89.45 percent respectively.

2. Adding a pyramidal section to the column assembly simplifies the implementation procedure, particularly in upper stories and increases $R_{\max }$ by 12.7 percent and decreases $\mathrm{M}_{\max }$ by 3.84 percent since it acts as a support. It also decreases the stress at the plate connected to the pyramidal section.

3. Using the stiffener increases the stiffness of the connection and causes torsion in the beam after creating a plastic hinge resulting in a 24.53 and 2.55 percent decrease in $R_{\max }$ and in $\mathrm{M}_{\max }$ respectively.

4. Since an I-shaped column in comparison with a box-shaped column cannot align with the short column, the connection plates yield earlier and the connection capacity diminishes such that $\mathrm{R}_{\max }$ and $\mathrm{M}_{\max }$ decrease by 11.7 and 10.03 percent respectively.

5. According to the findings of this study, pre-fabricate steel connections represent a high capacity and acceptable performance under cyclic loads. $\mathrm{R}_{\mathrm{y}}, \mathrm{R}_{\max }, \mathrm{M}_{\mathrm{y}}$ and $\mathrm{M}_{\max }$ were obtained 0.01266 rad., 0.0795 rad., 66.25 kN.m, 107.63 kN.m for Ct15 while 0.0032 rad., 0.0225 rad., 39.5 kN.m and 62.5 kN.m for FW respectively. Based on these results, the mentioned parameters of Ct15 are 295.65, 253.3, 67.72 and 72.2 percent which are higher than FW.

\section{REFERENCES}

[1] Liu, X., Pu, S., Zhang, A., Xu, A., Ni, Z., Sun, Y. and Ma, L., "Static and Seismic Experiment For Bolted-Welded Joint In Modularized Prefabricated Steel Structure", Journal Of Constructional Steel Research, 2015, Vol. 115, pp. 417-433.

[2] Ghassemieh, M., Jalalpour, M. and Gholampour, A., "Numerical Evaluation of the Extended Endplate Moment Connection Subjected to Cyclic Loading", Current Advances in Civil Engineering, 2014, Vol. 2, No. 1, pp. 35-43.

[3] Popov, E. and Tsai, K.C., "Performance of Large Seismic Moment Connections under Cyclic Loads", AISC Engineering Journal, 1989, Vol. 26, No. 2, pp. 51-60.

[4] Maggi, Y. I., Gonçalves, R. M., Leon, R. T. and Ribeiro, L. F. L., "Parametric Analysis of Steel bolted Endplate Connections Using Finite Element Modeling", Journal of Constructional Steel Research, 2005, Vol. 61, No. 5, pp. 689-708.

[5] AlHendi, H. and Celikag, M., "Parametric Study on Moment-rotation Characteristics of Reverse Channel Connections to Tubular Columns", Journal of Constructional Steel Research, 2015, Vol. 104, pp. 261-273.

[6] Kulkarni Swati, A. and Gaurang, V., "Study of Steel Moment Connection with and without Reduced Beam Section", Case Studies in Structural Engineering, 2014, Vol. 1, pp. 26-31.

[7] Gerami, M., Saberi, H., Saberi, V. and Saedi Daryan, A., "Cyclic Behavior of Bolted Connections with Different Arrangement of Bolts", Journal of Constructional Steel Research, 2011, Vol. 67, No. 4, pp. 690-705.

[8] Coelho, M. Girao., Bijlaard Frans, S.K. Gresnigt, N. and Simoes da Silva, L., "Experimental Assessment of the Behavior of Bolted T-stub Connections Made up of Welded Plates", Journal of Constructional Steel Research, 2004, Vol. 60, No. 2, pp. 269-311.

[9] Brunesi, E., Nascimbene, R. and Rassati, G.A., "Response of Partially-restrained Beam-to-column Connection under Cyclic Loads", Journal of Constructional Steel Research, 2014, Vol. 97, pp. 24-38.

[10] Arul Jayachandran, S., Marimuthu, V., Prabha, P., Seetharaman, S. and Pandian, N., "Investigation on the Behavior of Semi-rigid Endplate Connections", Advanced Steel Construction, 2009, Vol. 5, No. 4, pp. 432-451. 
[11] Brunesi, E., Nascimbene, R. and Rassati, G. A., "Seismic Response of MRFs with Partially-restrained Bolted Beam-to-column Connection through FE Analyses", Journal of Constructional Steel Research, 2015, Vol. 107, pp. 37-49.

[12] Pucinotti, R., "Prediction of Cyclic Moment-rotation Behavior for Top and Seat \& Web Angle Connections by Mechanical Model”, Advanced Steel Construction, 2007, Vol. 115, No. 1, pp. 530-552.

[13] Liu, X., Xu, A., Zhang, A., Ni, Z., Wang, H. and Wu, L., "Static and Seismic Experiment for Welded Joints in Modularized Prefabricated Steel Structure", Journal of Constructional Steel Research, 2015, Vol. 112, pp. 183-195.

[14] Liu, X., Pu, S., Zhang, A. and Zhan, X., "Performance Analysis and Design of Bolted Connections in Modularized Prefabricated Steel Structures", Journal Of Constructional Steel Research, 2017, Vol. 133, pp. 360-373.

[15] Min Yang, C. and Moon Kim, Y., "Cyclic Behavior of Bolted and Welded Beam-to-Column Joints”, Journal of Mechanical Sciences, 2007, Vol. 49, pp. 635-649.

[16] ATC-24, "Guidelines of Cyclic Seismic Testing on Components for Steel Structures", Redwood City, California, Applied Technology Council, 1992.

[17] Salmon, C. G. and Johnson, J. E. and Malhas, F. A., "Steel Structure Design and Behavior". 5rd ed., New York, Prentice Hall, 2008.

[18] Popov, EP. and Takhirov, SM., "Bolted Large Seismic Steel Beam-to-column Connections Part 1: Experimental Study", Engineering Structures, 2002, Vol. 24, No. 12, pp. 1523-1534.

[19] SAC Joint Venture, "Protocol for Fabrication, Inspection, Testing, and Documentation of Beam-column Connection Tests and Other Experimental Specimens", Report No. SAC/BD-97/02, 1997. 